\title{
OPEN Biological and environmental influences on motor coordination in Peruvian children and adolescents
}

\author{
Sara Pereira ${ }^{1,2 \bowtie}$, Alcibíades Bustamante ${ }^{3}$, Carla Santos ${ }^{1}$, Donald Hedeker ${ }^{4}$, Go Tani ${ }^{5}$, \\ Rui Garganta ${ }^{1}$, Olga Vasconcelos ${ }^{1}$, Adam Baxter-Jones ${ }^{6}$, Peter T. Katzmarzyk ${ }^{7}$ \& José Maia ${ }^{1}$
}

This study investigated the associations between biological and environmental factors and grossmotor coordination (GMC) in Peruvian children and adolescents. The sample comprised 7401 boys and girls, aged 6-14 years, recruited from three geographical regions: sea-level, Amazon and high-altitude. Biological variables included age, sex, height, BMI, physical fitness, stunting, and maturational status. Environmental influences included geographical region and school characteristics. Gross-motor coordination was tested with the Körperkoordinationstest für Kinder and the data analyzed by multilevel logistic regression. Results showed a high prevalence of below normal GMC scores. Sex, age, geographical area, biological maturation, BMI (normal versus overweight/ obesity), and stunting were all significant predictors of GMC. There was also an interaction between age, sex, and geographical area indicating that older girls who lived at sea-level and high-altitude were more likely to display below normal GMC scores. The school context was less important in predicting GMC problems than the interplay between biological characteristics and geographical region. These results suggest that early identification, as well as educational and pediatric care interventions, are of importance in reducing below normal GMC among Peruvian children and adolescents.

The description and interpretation of children and adolescents' physical status are of great importance ${ }^{1}$ given the known relationship with their health and well-being ${ }^{2}$. Moreover, healthy children and adolescents are more likely to succeed in school ${ }^{3}$, be physically active and more physically fit ${ }^{4}$, as well as have better motor coordination ${ }^{5}$.

Gross motor coordination (GMC) is defined as the harmonious and economical interaction of the musculoskeletal, nervous, and sensory systems that produce accurate and balanced motoric actions with minimal energy expenditure ${ }^{6}$. Children with below normal GMC scores typically experience difficulties in performing motor tasks. They also face challenges related to their daily activities, school performance and social participation ${ }^{7-9}$. The prevalence of GMC problems/disorders ranges from about 9- to $28 \%$ in children and adolescents ${ }^{10-12}$ and appears to be higher in countries with lower human development indexes ${ }^{13}$. Most experts agree that below normal GMC scores need to be addressed as early as possible to prevent extension into adulthood. If left unresolved these childhood GMC issues could interfere with the demands of future work and daily living activities ${ }^{14}$.

It has been reported that GMC levels vary substantially among children and adolescents, and that individual demographics, biological variables (e.g., age, sex, body mass index, physical fitness, gestational age), socioeconomic status, parental education, number of siblings, or birth order and environmental characteristics (e.g., time spent outdoors in playing spaces, parents' physical activity and family interactions), are modulating factors ${ }^{15-17}$. Available reports regarding the role of environmental factors in explaining GMC variation are limited and controversial $^{12,18,19}$. Therefore, new studies are needed to better understand these linkages. For example, Barnett et al. ${ }^{11}$ showed inconsistent results regarding the influence of socioeconomic status on GMC. These findings were like those of Niemistö et al. ${ }^{19}$ who studied children from three geographical regions of Finland, scattered

${ }^{1}$ CIFI2D, Faculty of Sport, University of Porto, R. Dr. Plácido da Costa 91, 4200-450 Porto, Portugal. ${ }^{2}$ CIDEFES, Lusófona University, Lisbon, Portugal. ${ }^{3}$ School of Physical Education and Sports, National University of Education Enrique Guzmán y Valle, La Cantuta, Lurigancho-Chosica, Peru. ${ }^{4}$ Department of Public Health Sciences, University of Chicago, Chicago, IL, USA. ${ }^{5}$ School of Physical Education and Sports, University of São Paulo, São Paulo, Brazil. ${ }^{6}$ College of Kinesiology, University of Saskatchewan, Saskatoon, Canada. ${ }^{7}$ Pennington Biomedical Research Center, Louisiana State University, Baton Rouge, LA, USA. ${ }^{\varpi}$ email: sara.s.p@hotmail.com 


\begin{tabular}{|c|c|c|c|c|c|}
\hline & & \multicolumn{4}{|c|}{ Gross motor coordination } \\
\hline & & \multirow{2}{*}{$\begin{array}{l}\text { Normal } \\
\mathrm{N}(\%)\end{array}$} & \multirow{2}{*}{\begin{tabular}{|l|} 
Below normal \\
$\mathrm{N}(\%)$ \\
\end{tabular}} & \multirow[b]{2}{*}{$\chi^{2}$} & \multirow[b]{2}{*}{ Comparisons $^{\mathrm{a}}$} \\
\hline & & & & & \\
\hline \multirow{2}{*}{ Age class } & $6-10$ years & $2647(72.0)$ & $1030(28.0)$ & \multirow{2}{*}{$216.035^{* * *}$} & \multirow{2}{*}{$11-14$ years $>6-10$ years } \\
\hline & $11-14$ years & $2069(55.6)$ & $1655(44.4)$ & & \\
\hline \multirow{2}{*}{ Sex } & Girls & $2036(49.4)$ & $2085(50.6)$ & \multirow{2}{*}{$824.334^{* * *}$} & \multirow{2}{*}{ Girls $>$ boys } \\
\hline & \begin{tabular}{|l|} 
Boys \\
\end{tabular} & $2680(81.7)$ & $600(18.3)$ & & \\
\hline \multirow{3}{*}{ Geographical area } & Sea-level & $749(51.0)$ & $719(49.0)$ & \multirow{3}{*}{$305.716^{* * *}$} & \multirow{3}{*}{$\begin{array}{l}\mathrm{S}>\mathrm{A} \\
\mathrm{H}>\mathrm{A}\end{array}$} \\
\hline & High-altitude & $1017(54.6)$ & $847(45.4)$ & & \\
\hline & Amazon region & $2950(72.5)$ & $1119(27.5)$ & & \\
\hline \multirow{2}{*}{ Stunting } & Non-stunted & $4269(64.2)$ & $2378(35.8)$ & \multirow{2}{*}{$7.150^{* *}$} & \multirow{2}{*}{ Stunted $>$ non-stunted } \\
\hline & Stunted & $447(59.3)$ & $307(40.7)$ & & \\
\hline \multirow{2}{*}{ Body Mass Index } & Normal weight & $3416(65.2)$ & $1820(34.8)$ & \multirow{2}{*}{$17.875^{* * *}$} & \multirow{2}{*}{$\mathrm{OW} / \mathrm{O}>\mathrm{NW}$} \\
\hline & Overweight/obese & $1300(60.0)$ & $865(40.0)$ & & \\
\hline \multirow{3}{*}{ Physical fitness } & Low & $950(51.6)$ & $892(48.4)$ & \multirow{3}{*}{$266.569^{* * *}$} & \multirow{3}{*}{$\mathrm{L}>\mathrm{M}>\mathrm{H}$} \\
\hline & Medium & $2339(63.0)$ & $1375(37.0)$ & & \\
\hline & High & $1427(77.3)$ & $418(22.7)$ & & \\
\hline
\end{tabular}

Table 1. Child-level characteristics by gross motor coordination. ${ }^{a}$ Direction of association for below normal GMC scores. ${ }^{* *} \mathrm{p}<0.01 ;{ }^{* * *} \mathrm{p}<0.001$.

by residential density areas. Previous studies have rarely explored the impact of putative covariates that influence children's chances of having below normal GMC, and instead mostly concentrated on the associations with physical fitness and body composition ${ }^{12,20-22}$.

Another issue of interest is geographical location (e.g., land elevation levels), a possible marker of a child's environmental exposure. Environmental differences within countries may play an important role in shaping motor and GMC development and thus needs to be considered ${ }^{23}$. Peru can be described in terms of three broad regions: the arid Coastal region in the west at sea level, the Sierra central region at high-altitude and the forested Amazonia in the east. Systematic differences in children and adolescents' lifestyles in these three regions are well known, as they have vastly different daily chores and subsistence activities ${ }^{24}$. All of these environmental issues are known to exert different influences on an individual's growth and development ${ }^{25}$. For example, de Chaves et al. ${ }^{12}$ reported that Peruvian children and adolescents living at sea level or at high-altitude were more likely to suffer from GMC difficulties than those living in the Amazon region.

School characteristics are also important and commonly examined correlates with respect to GMC. Children and adolescents spend a large portion of their waking hours at school ${ }^{26}$, and it is expected that school characteristics play an important role in addressing and resolving below normal GMC scores. For example, Santos et al. ${ }^{23}$ reported that in Peruvian children, $31 \%$ of the total variance in GMC (based on continuous raw scores) was explained by school characteristics, namely school size, availability of playgrounds with obstacles, whether there was an indoor multi-sport complex, and if physical education classes were of longer duration. It is likely that there is an interaction between the natural and built environments, and individual characteristics on GMC but this is seldom tested. To our knowledge, there is a lack of information on the interplay between GMC and a wide range of biological and environmental factors; this is especially with respect to those identified as performing below normal.

To better understand this integrative questioning, an appropriate analytical framework is required. Using a multilevel statistical model, which accounts for the nested structure of the data, it is possible to probe the network of independent and interaction links between biological and environmental characteristics and GMC within and between individuals. Specifically, the aims of this study were to expand the previous work of our research group $^{12,27}$ and address the following questions: (1) Are age, sex and geographical areas associated with children and adolescents' below normal GMC during childhood and adolescence? (2) Do age-by-sex, age-by-geographical area, and sex-by-geographical area interactions predict below normal GMC? (3) Do age-by-sex-by-geographical area interactions predict below normal GMC? (4) What are the impacts of child-level characteristics on the likelihood of below normal GMC? And, (5) Do school-level variables influence below normal GMC? We hypothesized that age, sex, child and school level characteristic's, geographical regions and their interactions would be associated with below normal GMC.

\section{Results}

Descriptive statistics. Table 1 shows the child-level characteristics by GMC level (normal and below normal). An increase in the prevalence of below normal GMC scores from 6-10 years to 11-14 years was observed $\left(\chi^{2}=216.035, \mathrm{p}<0.05\right)$. Girls $(50.6 \%)$ had higher prevalence of below normal GMC scores compared to boys $\left(18.3 \%, \chi^{2}=824.330, \mathrm{p}<0.05\right)$. Children and adolescents from sea-level $(49.0 \%)$ and high-altitude $(45.4 \%)$ had a higher prevalence of below normal GMC scores compared to their Amazonian peers (27.5\%). Moreover, children and adolescents with stunting had a higher prevalence than non-stunted children and adolescents $(40.0 \%$ vs $\left.5.8 \%, \chi^{2}=7.150, p<0.05\right)$. A similar result was observed regarding weight status in which youth who were 


\begin{tabular}{|c|c|c|}
\hline & $\mathbf{n}$ & $\%$ \\
\hline \multicolumn{3}{|l|}{ School setting } \\
\hline Mixed & 3 & 16.7 \\
\hline Urban & 15 & 83.3 \\
\hline \multicolumn{3}{|l|}{ Policies and practices for physical activity } \\
\hline No & 8 & 44.4 \\
\hline Only policies & 3 & 16.7 \\
\hline Only practices & 7 & 38.7 \\
\hline \multicolumn{3}{|l|}{ Playground obstacles } \\
\hline Without obstacles & 15 & 83.3 \\
\hline With obstacles & 3 & 16.7 \\
\hline \multicolumn{3}{|l|}{ Indoor multi-sport complex } \\
\hline No & 12 & 66.7 \\
\hline Yes & 6 & 33.3 \\
\hline \multicolumn{3}{|l|}{ Physical education classes duration } \\
\hline$\leq 90 \mathrm{~min}$ & 8 & 44.4 \\
\hline$>90 \mathrm{~min}$ & 10 & 55.6 \\
\hline \multicolumn{3}{|l|}{ Extracurricular activities } \\
\hline No & 4 & 22.2 \\
\hline Yes & 14 & 77.8 \\
\hline \multicolumn{3}{|c|}{ School infrastructures available outside of school activities } \\
\hline No & 11 & 61.1 \\
\hline \multirow[t]{2}{*}{ Yes } & 7 & 38.9 \\
\hline & Mean (SD) & Range \\
\hline Number of students per school & $453(263)$ & $96-1200$ \\
\hline Active time during physical education class & $78(16)$ & $50-110$ \\
\hline
\end{tabular}

Table 2. Descriptive statistics of the school-level characteristics [counts (n), frequencies (\%), means, standard deviations (SD) and ranges].

overweight or obese had a higher prevalence of below normal GMC scores than their normal weight peers $\left(40.0 \%\right.$ vs $\left.34.8 \%, \chi^{2}=17.875, p<0.05\right)$. Finally, those with high levels of physical fitness had a lower prevalence of GMC problems (22.7\%) when compared with those showing low (48.4\%) and medium (37.0\%) levels of fitness.

School-level characteristics are shown in Table 2. Eighty-three percent of schools were located in urban areas, with the number of students per school ranging from 96 to 1200 . Furthermore, $83.3 \%$ of schools had a playground without obstacles, and $33.3 \%$ had access to an indoor multi-sport complex. Forty-four percent of schools had neither policies nor practices for physical activity, whereas $16.7 \%$ had policies and $38.9 \%$ had practices for physical activity. In 55.6\% of schools, physical education classes were more than $90 \mathrm{~min}$ in duration once a week, and children and adolescents active time during classes was, on average, $78 \mathrm{~min}$. Additionally, $77.8 \%$ of schools offered extracurricular activities, and 38.9\% allowed students to use school infrastructures outside of school activities.

Results of the multilevel logistic analysis are presented in Table 3. The null model (data not shown) indicated that $15 \%$ of the total variance in GMC categories was explained by school-level characteristics, with the remaining $85 \%$ associated with distinct child and adolescent traits.

Question 1: Are age, sex and geographical area associated with children and adolescents' chances of having below normal GMC scores? Model 1 results show that older individuals were more likely to exhibit below normal GMC scores than their younger peers $(\mathrm{OR}=1.686$; $95 \% \mathrm{CI} 1.454-1.956)$. Moreover, boys $(\mathrm{OR}=0.183 ; 95 \% \mathrm{CI}$ $0.161-0.209)$ and those living in the Amazon region $(\mathrm{OR}=0.366$; $95 \% \mathrm{CI} 0.230-0.581)$ were less likely to show below normal GMC scores than girls and their sea-level peers, respectively.

Question 2: Do age-by-sex, age-by-geographical area, and sex-by-geographical area interactions condition below normal GMC scores? Model 2 was a better fit of the data than Model $1\left(\chi^{2}=21.04,5 \mathrm{df}, \mathrm{p}<0.001\right)$ as indicated by a significant drop in the deviance statistic. The model also found that interaction effects had statistically independent effects. The age-by-sex interaction results revealed that although both boys and girls increased the probability of having below normal GMC scores from 6-10 years through to 11-14 years, the increase with age was greatest in girls (see Fig. 1a). For the age-by-geographical area interaction, a significant effect $(\mathrm{p}<0.05)$ was only observed between sea-level and amazon regions, indicating that sea-level youth have a greater chance of having below normal GMC scores. Figure 1b shows a lower probability for Amazonian subjects in both age classes $(6-10$ years $=23 \%$ and $11-14$ years $=36 \%)$ to demonstrate below normal GMC scores when compared to sea-level peers $(6-10$ years $=45 \%$ and $11-14$ years $=53 \%)$ and high-altitude peers $(6-10$ years $=45 \%$ and 11-14 years $=50 \%)$. However, it is important to note that the difference in rates of below normal GMC scores for Amazonian subjects tend to be higher $(\sim 14 \%)$ than their counterparts from sea-level $(\sim 8 \%)$ and high-altitude $(\sim 5 \%)$ across age. Finally, there was a significant sex-by-geographical area interaction (Fig. 1c), but only between sea-level and high-altitude Peruvian youth of both sexes. 


\begin{tabular}{|c|c|c|c|c|c|}
\hline \multirow[b]{2}{*}{ Variables } & Model 1 & Model 2 & Model 3 & Model 4 & Model 5 \\
\hline & OR $(95 \% \mathrm{CI})$ & OR $(95 \% \mathrm{CI})$ & OR $(95 \% \mathrm{CI})$ & OR $(95 \% \mathrm{CI})$ & OR $(95 \% \mathrm{CI})$ \\
\hline Age (11-14 years) & $1.686(1.454-1.956)^{* * *}$ & $1.621(1.217-2.159)^{* *}$ & $1.268(0.919-1.749)$ & $0.556(0.385-0.801)^{* *}$ & $0.582(0.406-0.835)^{* *}$ \\
\hline Sex (boys) & $0.183(0.161-0.209)^{* * *}$ & $0.338(0.198-0.578)^{* * *}$ & $0.221(0.119-0.409)^{* * *}$ & $0.126(0.064-0.247)^{\star * *}$ & $0.077(0.037-0.160)^{* * *}$ \\
\hline Geographical area (high-altitude) $^{\mathrm{e}}$ & $0.904(0.554-1.476)$ & $1.263(0.709-2.246)$ & $1.239(0.669-2.293)$ & $1.514(0.740-3.098)$ & $1.505(0.369-6.148)$ \\
\hline Geographical area (amazon region) $^{e}$ & $0.366(0.230-0.581)^{* * *}$ & $0.360(0.212-0.614)^{*}$ & $0.319(0.181-0.561)^{* * *}$ & $0.425(0.220-0.821)^{\star}$ & $0.711(0.279-1.811)$ \\
\hline \multicolumn{6}{|l|}{ Interactions (two-way) } \\
\hline Age-by-sex ${ }^{c}$ & & $0.722(0.564-0.925)^{*}$ & $1.918(1.008-3.651)^{\star}$ & $0.872(0.438-1.737)$ & $0.703(0.361-1.367)$ \\
\hline $\begin{array}{l}\text { Age-by-geographical area (11-14 years/high- } \\
\text { altitude) }\end{array}$ & & $0.886(0.591-1.330)$ & $1.057(0.662-1.690)$ & $0.854(0.520-1.403)$ & $0.825(0.496-1.372)$ \\
\hline $\begin{array}{l}\text { Age-by-geographical area (11-14 years/amazon- } \\
\text { region) }\end{array}$ & & $1.450(1.019-2.063)^{*}$ & $2.131(1.420-3.197)^{\star * \star}$ & $2.428(1.570-3.756)^{* * *}$ & $2.406(1.575-3.674)^{* * *}$ \\
\hline Sex-by-geographical area (male/high-altitude) & & $0.560(0.319-0.984)^{*}$ & $0.786(0.395-1.565)$ & $0.578(0.275-1.212)$ & $0.947(0.427-2.100)$ \\
\hline Sex-by-geographical area (male/amazon region) & & $0.673(0.387-1.170)$ & $1.252(0.395-1.565)$ & $1.120(0.550-2.282)$ & $1.838(0.848-3.980)$ \\
\hline \multicolumn{6}{|l|}{ Interactions (three-way) } \\
\hline $\begin{array}{l}\text { Age-by-sex-by-geographical area (11-14 years/ } \\
\text { male/high-altitude) }\end{array}$ & & & $0.439(0.205-0.944)^{*}$ & $0.512(0.229-1.142)$ & $0.633(0.289-1.386)$ \\
\hline $\begin{array}{l}\text { Age-by-sex-by-geographical area (11-14 years/ } \\
\text { male/amazon region) }\end{array}$ & & & $0.247(0.119-0.514)^{* * *}$ & $0.269(0.124-0.581)^{* \star}$ & $0.325(0.154-0.687)^{* *}$ \\
\hline \multicolumn{6}{|l|}{ Other child-level characteristics } \\
\hline Maturity offset & & & & $1.820(1.651-2.005)^{* * *}$ & $1.823(1.652-2.011)^{* * *}$ \\
\hline Stunting $(\text { yes })^{\mathrm{b}}$ & & & & $1.491(1.232-1.804)^{* * *}$ & $1.484(1.227-1.795)^{* * *}$ \\
\hline Body mass index ${ }^{\mathrm{d}}$ (overweight/obese) & & & & $1.291(1.131-1.473)^{* * *}$ & $1.284(1.125-1.465)^{* * *}$ \\
\hline Physical fitness (medium) & & & & $0.419(0.361-0.487)^{* * *}$ & $0.419(0.360-0.486)^{* * *}$ \\
\hline Physical fitness (high) & & & & $0.150(0.122-0.185)^{* * *}$ & $0.150(0.122-0.184)^{* * *}$ \\
\hline \multicolumn{6}{|l|}{ School-level characteristics } \\
\hline School setting (urban) ${ }^{\mathrm{f}}$ & & & & & $1.030(0.487-2.178)$ \\
\hline Number of students ${ }^{g}$ & & & & & $0.999(0.998-1.000)$ \\
\hline $\begin{array}{l}\text { Policies or practices for physical activity (only } \\
\text { policies) }\end{array}$ & & & & & $3.197(1.014-10.080)^{*}$ \\
\hline $\begin{array}{l}\text { Policies or practices for physical activity (only } \\
\text { practices) }\end{array}$ & & & & & $0.948(0.504-1.783)$ \\
\hline Playground obstacles (with obstacles) ${ }^{\mathrm{j}}$ & & & & & $1.597(0.881-2.897)$ \\
\hline Indoor multisports (yes) $)^{j}$ & & & & & $1.551(0.730-3.296)$ \\
\hline Physical education classes duration $(\geq 90 \mathrm{~min})^{1}$ & & & & & $0.979(0.586-1.638)$ \\
\hline Active time during physical education classes & & & & & $1.010(0.992-1.027)$ \\
\hline Extracurricular activities (yes) ${ }^{j}$ & & & & & $0.525(0.279-0.987)^{*}$ \\
\hline Deviance & 8210.68 & 8189.64 & 8174.48 & 7740.20 & 7729.12 \\
\hline Number of parameters & 6 & 11 & 13 & 18 & 27 \\
\hline $\begin{array}{l}\Delta \text { in Deviance from previous model ( } \Delta \text { in number } \\
\text { of parameters) }\end{array}$ & $775.15(4)^{* * *}$ & $21.04(5)^{* * *}$ & $15.16(2)^{* * *}$ & $434.28(5)^{\star * *}$ & $11.08(9)$ \\
\hline
\end{tabular}

Table 3. Parameters estimates [odds ratios (OR) and $95 \%$ confidence intervals] and variance components for gross motor coordination. ${ }^{* *} \mathrm{p}<0.001{ }^{* *} \mathrm{p}<0.01$; ${ }^{\star} \mathrm{p}<0.05$; ${ }^{\mathrm{a}}$ normal growth is the reference; ${ }^{\text {birls }}$ are the reference; ${ }^{c}$ thiness/normal weight is the reference; ${ }^{\mathrm{d}}$ Amazon region is the reference; ${ }^{\mathrm{e}}$ mixed is the reference; ${ }^{\mathrm{f}}$ number of students divided by 10 ; ${ }^{\mathrm{g}}$ no policies nor practices is the reference; ${ }^{\mathrm{h}}$ without obstacles is the reference; ${ }^{i}$ no is the reference; ${ }^{j}<90$ min is the reference.

Question 3: If the two-way interactions are significant, does an age-by-sex-by-geographical area interaction predict below normal GMC scores? Model 3 was a better fit of the data than Model $2\left(\chi^{2}=15.16,2 \mathrm{df}, \mathrm{p}<0.001\right)$ indicating the importance of three-way interactions in both categories. Figure 2 shows that girls from the Amazon region had higher increases of the probability of having below normal GMC scores between 6 and 10 years through to 11-14 years (23\%) than sea-level (5\%) and high-altitude (3\%) peers. Boys showed a different pattern: at 6-10 years boys from sea-level and high-altitude had equal probability of having below normal GMC scores (24\%) and higher probability than Amazon region (11\%). Additionally, boys from high-altitude and Amazon region from 6-10 years to 11-14 years displayed residual increases in their probability of having below normal GMC scores ( $2 \%$ and 3\%, respectively), although boys from the sea-level presented higher increases in their probability (19\%).

Question 4: What are the relationships of child-level characteristics on the likelihood of below normal GMC scores? Model 4 was a better fit of the data than Model $3\left(\chi^{2}=434.28,5 \mathrm{df}, \mathrm{p}<0.001\right)$, and showed that those advanced in their biological maturation $(\mathrm{OR}=1.820 ; 95 \% \mathrm{CI} 1.651-2.005)$, stunted $(\mathrm{OR}=1.491 ; 95 \% \mathrm{CI}$ $1.232-1.804)$, and being overweight or obese $(\mathrm{OR}=1.291 ; 95 \% \mathrm{CI} 1.131-1.473)$ were more likely to have below normal GMC scores. However, Peruvians with medium $(\mathrm{OR}=0.419 ; 95 \% \mathrm{CI} 0.361-0.487)$ and higher $(\mathrm{OR}=0.150$; 
a)

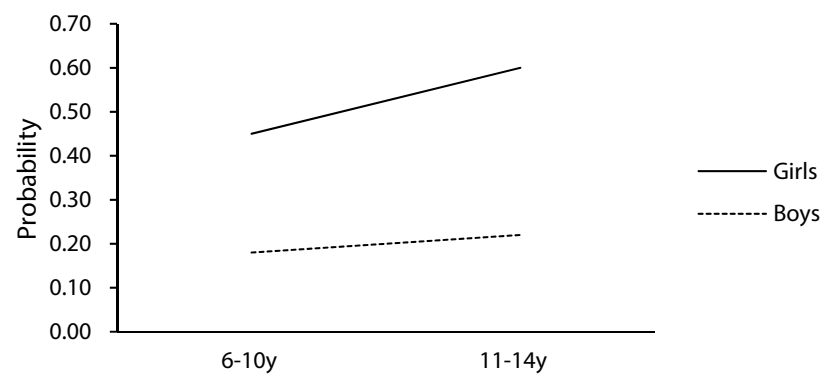

b)

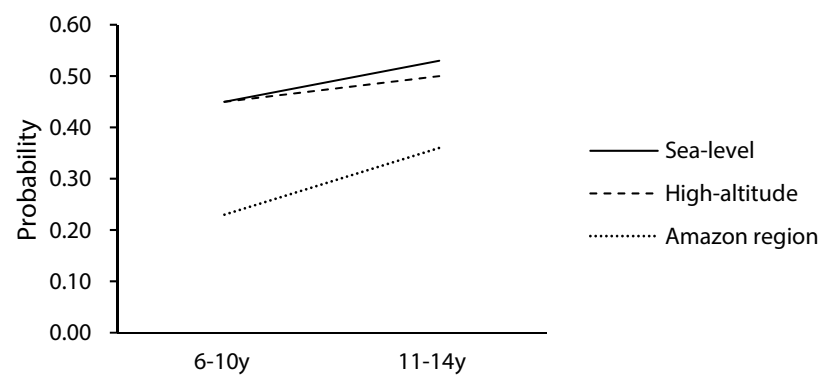

c)

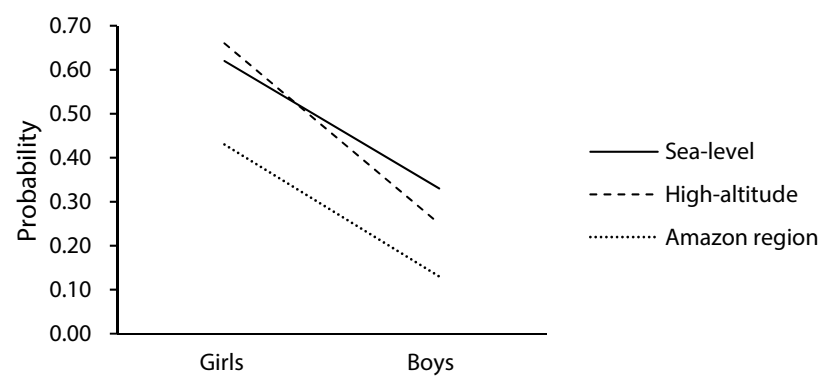

Figure 1. Plots of probabilities of having below normal GMC scores: age-by-sex (a) age-by-geographical location (b) and sex-by-geographical location (c) interactions.

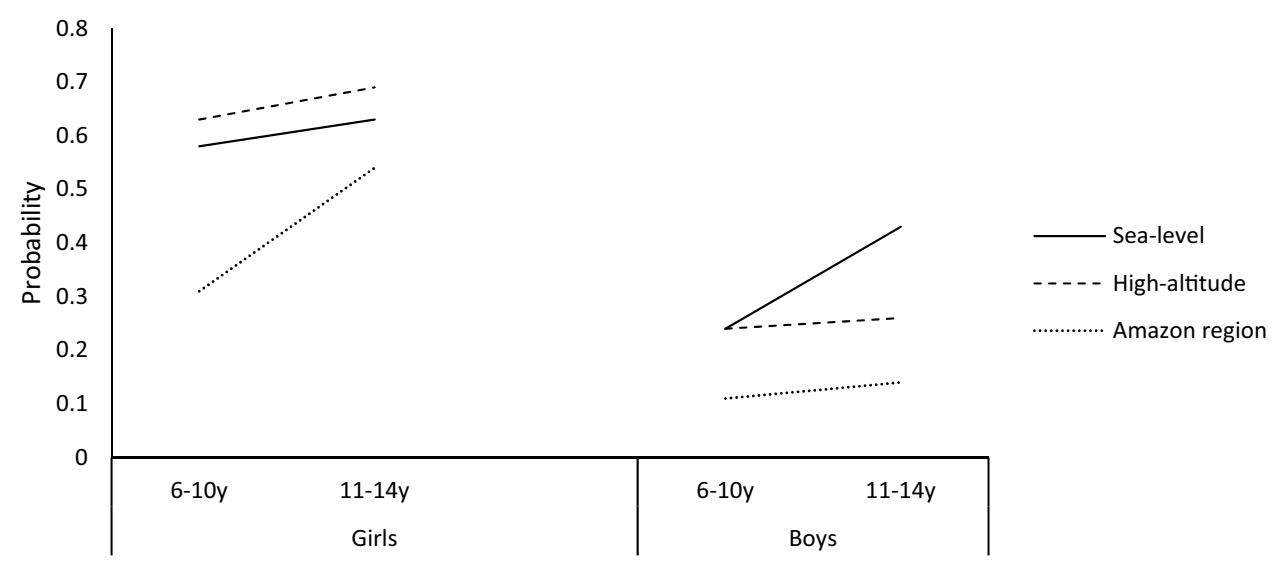

Figure 2. Plots of probabilities of having below normal GMC scores: age-by-sex-by-geographical area interaction. 
95\%CI 0.122-0.185) physical fitness levels had lower odds ratios, i.e., they were more protected of displaying below normal GMC scores than their peers with low physical fitness levels.

Question 5: Do school level variables influence below normal GMC scores? Finally, when school-level covariates were added (Model 5), no improvement in model fit was found relative to Model $4\left(\chi^{2}=11.08,9 \mathrm{df}, \mathrm{p}>0.05\right)$. This suggests that, after accounting for individual characteristics and geographical location as well as their significant interactions, school-level characteristics did not significantly predict Peruvian children and adolescents' chances of having below normal GMC scores.

\section{Discussion}

There is little doubt that identifying children with below normal GMC scores, and their putative correlates, during a child's growth has important long term educational and pediatric care implications ${ }^{28}$. We believe that the uniqueness of the present study is in the examination of the interactions between individual and environmental characteristics in explaining the presence of below normal GMC scores during childhood. This is of particular importance for children living in developing countries, such as Peru, but can also be extended to other SouthAmerican children living in regions marked by geographical, cultural, and socioeconomic differences.

An important finding of this study is that the main fraction of GMC categories' variance (85\%) was explained by Peruvians' individual characteristics, and this is similar to a report with Portuguese children ${ }^{18}$. Also consistent with previous results is the fact that Peruvian girls are more likely to display below normal GMC scores than Peruvian boys ${ }^{12,27}$. This sex difference in GMC suggests a complex interplay between biological and cultural factors, which are probably linked to differences in sport participation, daily chores and the different physical activities chosen by girls compared to boys. For example, Peruvian girls tend to spend their time after school in home activities (e.g., cleaning, cooking, etc.) whereas boys spend their time in sports' participation and other varied physical activities ${ }^{29}$.

We showed that older Peruvians were more likely to have below normal GMC scores, a result similar to a finding in Flemish children aged 5-12 years ${ }^{30}$. One plausible explanation for such results may be linked to differences in the timing and tempo of the adolescent growth spurt. This period of growth is marked by an asynchrony in the growth of different parts of the body ${ }^{31,32}$ that can adversely affect motor control, a phenomenon termed "clumsiness" or "adolescent awkwardness" 33 . It is also possible that interindividual differences, within the same sex, in biological maturation timing and tempo may explain our results.

For example, Bisi and Stagni ${ }^{34}$ in an experimental study compared the gait performance of fast growing (height increase $>3 \mathrm{~cm}$ in 3 months) and slow growing (height increase $<1 \mathrm{~cm}$ in 3 months) male adolescents. It was found that during a walking task the association with the timing of the adolescent growth spurt influenced gait variability, smoothness, and regularity. Additionally, whereas the slow and fast-growing children performed some motor tasks awkwardly, those who grew steadily were able to cope with their physical growth changes and thus maintained smoothness and regularity in some motor tasks. This result was also previously reported in Flemish male soccer players ${ }^{35}$ as well as in healthy Belgium boys ${ }^{36}$. Indeed, these studies showed a temporary decline in performance during the growth spurt. Further, Loko et al. ${ }^{37}$ working with Estonian adolescent girls, reported plateaus and declines in multiple motor skills' performance around the adolescent growth spurt. In spite of these findings, more longitudinal studies are still required to better understand the potential associated mechanisms ${ }^{38}$, namely sensorimotor function and sex differences ${ }^{38,39}$. More specifically, boys and girls experience puberty at different timing 23 and at this time the sensorimotor mechanisms are not fully mature such as neurocognitive processing capabilities, neuromuscular control and coordination, and regulation of postural $\mathrm{control}^{38}$. These issues allied to the rapid growth spurt may help explain the higher prevalence of below normal GMC in older Peruvians.

The main challenge of the present study was to investigate how geographical areas interacted with individuallevel characteristics (age and sex) in predicting below normal GMC scores. Based on a three-way interaction of age-by-sex-by-geographical area we showed that older girls living at sea level were more likely to display below normal GMC scores, whilst the youngest boys from the Amazonian region were less likely to have below normal GMC scores. These results emphasize the importance of identifying differences between these three regions that are contributing to different probabilities of below normal GMC scores, especially between the sea level and the Amazon regions. One possible explanation could be differences in their natural, sociodemographic, health care and cultural characteristics (see Table 4) that influence lifestyle behaviors and routine activities. For example, the sea-level region has a higher human developmental index, higher income and consequently a better urban development and higher population density. In such environments children tend to adopt certain lifestyle behaviors, and other daily routine activities, closer to youth from developed countries i.e., more sedentary activities and lower levels of physical activity. In fact, Sharma et al. ${ }^{40}$ showed that $78 \%$ of Peruvian adolescents living at sea-level do not meet the WHO recommendations for moderate-to-vigorous physical activity. In contrast, children and adolescents from the Amazon region tend to live in cities with less population density but larger areas. Peru's sea-level region represents $11 \%$ of the total area of the country but it is occupied by $65 \%$ of the total population, while the Amazon region represents $60 \%$ of the total area but only $5 \%$ of the total population reside in this region (approximately 1.6 million) ${ }^{41}$. Moreover, most families in the Amazon region are dependent on agricultural production and children tend to assist their parents with these activities, especially outside of school hours. The time spent in agricultural pursuits may be providing these children with rich opportunities to play freely in the natural environments which in turn increases their physical activity and improves their GMC.

Finally, when considering main effects of other individual characteristics, our results are fairly consistent with previous research. We found that biological maturation (favoring those less advanced), nutritional status (favoring normal weight), stunting (favoring non-stunted) and physically fitness (favoring higher levels) were all negatively associated with below normal GMC scores ${ }^{15,27}$. These results are important pointers regarding 


\begin{tabular}{|c|c|c|c|}
\hline \multicolumn{4}{|l|}{ Natural characteristics } \\
\hline Altitude $(\mathrm{m})$ & 58 & 751 & 4107 \\
\hline Precipitation, and temperature (average) & Arid; semi-warm $\left(18^{\circ} \mathrm{C}\right)$ & Rainy; warm $\left(24^{\circ} \mathrm{C}\right)$ & Rainy; cold $\left(12^{\circ} \mathrm{C}\right)$ \\
\hline Humidity & Humid & Very humid & Humid \\
\hline \multicolumn{4}{|l|}{ Socioeconomic characteristics } \\
\hline Human development index & 0.72 & 0.52 & 0.44 \\
\hline Per capita family income & 1440.6 & 785.1 & 512.7 \\
\hline Primary production & Trade/tourism & Agriculture/tourism & Stockbreeding/agriculture \\
\hline \multicolumn{4}{|l|}{ Demographic characteristics } \\
\hline Population (total) & 8.564 .867 & 411.011 & 1.272 .890 \\
\hline Population density (people $/ \mathrm{km}^{2}$ ) & 236.6 & 10.2 & 27.7 \\
\hline \multicolumn{4}{|l|}{ Basic access to health care } \\
\hline Health center & Yes & No & No \\
\hline Public hospital & No & Yes & Yes \\
\hline Private clinic & Yes & No & No \\
\hline Hospital campaigns and tracking at school & No & Yes & Yes \\
\hline \multicolumn{4}{|c|}{ Infrastructure for physical activity and sports available } \\
\hline Parks & Yes & Yes & Yes \\
\hline Playground & Yes & Yes & Yes \\
\hline Pool & Yes & Yes & Yes \\
\hline Multisport indoor & Yes & Yes & Yes \\
\hline Multisport outdoor & No & Yes & Yes \\
\hline Gymnastics complex & No & No & No \\
\hline
\end{tabular}

Table 4. Natural, socioeconomic, demographic, health care and cultural features of the three regions.

their adverse and/or protective effects of such characteristics on the development of below normal GMC scores. More specifically, nutritional status and stunting are risk factors while physical fitness is a protective factor in predicting below normal GMC scores. Moreover, these findings are concordant not only with other Peruvian studies ${ }^{12,27}$ but also with data from Portuguese ${ }^{16}$ and Flemish ${ }^{30,42}$ children and adolescents.

There is little doubt that the school environment is important when considering optimal physical growth, fundamental motor skills and GMC development ${ }^{6}$. Our findings showed that $15 \%$ of the total variance in GMC levels was accounted for by the school context. However, in the final model (Model 5) when we added school characteristics after adjusting for individual characteristics, natural environments and their interaction, this model did not fit the data better than the previous one (Model 4). This result suggests that individual characteristics and the natural environment play a more important roles than school characteristics in the prediction of GMC problems in these Peruvian children and adolescents. This reinforces our previous suggestion about the differences between regions being highly important in explaining differences between children and adolescents with below normal GMC scores. This reiterates the importance of population lifestyles and highlights the importance of further research between different countries and regions, as well as contrasting high-income versus low-income countries.

This study is not without limitations. Firstly, the cross-sectional design does not allow any causal interpretation into the dynamics of individual and environmental complex relationships on changes in below normal GMC scores development. Secondly, the unbalanced sample sizes between regions (19.8\% sea-level, 25.2\% high-altitude and $55 \%$ amazon) limits the generalization of the results to all Peruvian youth. Thirdly, we did not have any information on other behaviors that could have influenced the links between stunting and below normal GMC scores, such as lifestyle behaviors (e.g., physical activity). Finally, we did not have any information about aspects of the home environment that may have interacted with individual characteristics and their development, which, in turn, may have had a protective or negative effect on GMC problems.

In conclusion, we showed a high prevalence of below normal GMC scores in Peruvian children and adolescents which were more pronounced in girls, who were aged 11-14 years from sea-level regions. Further, these findings highlight the important influences of individual and environmental characteristics on below normal GMC scores. This finding has key implications for physical education teachers to promote adequate levels of GMC development, as well as for pediatric care within local health-systems. Altogether, these results revealed the need to offer distinct physical education programs according to regions (i.e., sea level, high-altitude and amazon region) to accommodate their dissimilar characteristics. Further, early identification of overweight/ obesity status, stunting and physical fitness levels aligned with biological maturation may also help to implement precise intervention programs tailored to children and adolescents' characteristics. If subjects differ in some characteristics that condition their GMC unfolding, then there is a need to develop suitable pediatric care to foster and enhance their healthy growth and proper motor development. 


\section{Methods}

Participants and geographical area of residence. Participants in the study were drawn from "The Peruvian Health and Optimist Growth Study", which was conducted between November 2009 and July 2010. This study investigated the relationships between physical growth, motor development and health in Peruvian children and adolescents and their families ${ }^{43}$. Participants were recruited from 18 randomly chosen schools from the 78 schools in these three regions, and the original sample consisted of 10,424 boys and girls 6-17 years of age. Complete data were obtained from 7401 participants (4121 girls; 3280 boys 6 to 14 years old) —the age range of the GMC test battery was from 5 to 14.99 years.

Given the country's heterogeneity in geography, participants came from three distinct regions: sea-level, Amazon region and high-altitude. Barranco was the chosen city at sea-level in the Lima region. The cities of La Merced and San Ramon in the Chanchamayo district represented the Amazon region, and the Junín district was used to represent the high-altitude location. Participants included in the present study were natives of their respective regions (non-immigrants). Information with regards to birthplace and current place of residence was collected from individual's identity cards. Table 4 shows the distinct characteristics of these geographical locations, based on information provided by National Institute of Statistics and Informatics (INEI) ${ }^{44}$, city-halls ${ }^{45-47}$ and the digital platform of the Ministry for the Environment ${ }^{48}$.

Written informed consent was obtained from legal guardians, and the project was approved by the local school and political authorities, as well as by the Ethics Committee of the National University of Education Enrique Guzmán y Valle (UNE EGyV). All methods were performed in accordance with the relevant guidelines and regulations. Moreover, the study was performed in accordance with the ethical standards established in the Declaration of Helsinki.

Outcome variable. Gross motor coordination. Gross motor coordination was assessed using the Körperkoordinationtest für Kinder (KTK), developed by Kiphard and Schilling ${ }^{49}$ for children and adolescents aged 5-14.99 years of age. This test battery has systematically been used in European ${ }^{50}$, African ${ }^{51}$ and SouthAmerica populations ${ }^{12,52}$. The KTK is explained in detail elsewhere ${ }^{39}$. In brief, the battery contains four tests: walking backwards along a balance beam, hopping on one foot, jumping sideways, and moving sideways on boxes. A total KTK score is obtained from summing the scores obtained from each test. This unweighted sum of the scores, adjusted for age and sex, is named as the motor quotient (MQ), and has the following categories: (i) not possible (MQ < 56); (ii) severe motor disorder (MQ 56-70); (iii) moderate motor disorder (MQ 71-85); (iv) normal (MQ 86-115); (v) good (MQ 116-130); (vi) high (MQ $\geq 131$ ). For the present study, we only considered two broad categories: $M Q>85$ as 'normal' GMC, and $M Q \leq 85$ as 'below normal' GMC, as recommended by Schilling ${ }^{53}$. In our statistical models, normal GMC was used as the reference category. ANOVA-based intraclass correlation reliability estimates of children and adolescents GMC performance ranged from 0.78 in the moving sideways test to 0.92 in the walking backwards test.

Exposure variables. Anthropometry. Body measurements were made according to standardized protocols ${ }^{28}$. Height and sitting height were measured using a portable stadiometer (Sanny, Model ES-2060) with the subject's head positioned in the Frankfurt plane, to the nearest $0.1 \mathrm{~cm}$. Body mass was measured to the nearest $0.1 \mathrm{~kg}$ using a digital scale (Pesacon, Model IP68). Technical error of measurement (intra-observer error) was $0.2 \mathrm{~cm}$ for height, $0.1 \mathrm{~cm}$ for sitting height, and $0.1 \mathrm{~kg}$ for body mass. BMI was calculated by dividing weight $(\mathrm{kg})$ by height squared $\left(\mathrm{m}^{2}\right)$.

Stunting and body weight status. Stunting (height-for-age) and body weight status (BMI-for-age) were predicted using age- and sex-specific WHO Child Growth Standards ${ }^{54,55}$. Two stunting groups were created: normal growth [height-for-age Z score $\geq-2$ standard deviation (SD)], and stunted growth (height-for-age $\mathrm{Z}$ score $<-2$ SD). Normal growth was used as the reference category in the models. Three body weight status groups were created: thinness (BMI-for-age $<-2 \mathrm{SD}$ ), normal weight (BMI-for-age between $\geq-2 \mathrm{SD}$ to $\leq 1 \mathrm{SD}$ ), and overweight/obese (BMI-for-age $>1 \mathrm{SD}$ ). However, given that only 40 subjects were classified with thinness ( $0.5 \%$ of the sample, representing 25 females and 15 males, 2 from sea-level, 15 from high-altitude and 23 from Amazon region), in the final models only normal weight and overweight/obese groups were considered and a thinness/normal weight grouping was used as the reference category.

Biological maturation. Biological maturation was assessed using a measure of somatic maturity predicted from anthropometrics to calculate a maturity offset value ${ }^{56}$. Maturity offset (years from peak height velocity) is an estimated temporal distance and is expressed in decimal years. Age at peak height velocity (PHV) is calculated as chronological age at assessment minus maturity offset. A positive $(+)$ maturity offset indicates the number of years the participant is beyond attainment of PHV, whereas a negative (-) maturity offset represents the number of years the participant is before attaining PHV. This method has been widely used in children and adolescents $^{57-59}$ and was previously used in other Peruvian studies ${ }^{25,60}$.

Physical fitness. Physical fitness was assessed using four tests: handgrip strength (static muscle strength component); standing long jump (explosive muscle strength component); shuttle-run (speed and agility component); and $12 \mathrm{~min}$ run (cardiorespiratory component). These tests are part of the EUROFIT test battery ${ }^{61}$ and the American Alliance for Health, Physical Education, Recreation and Dance (AAHPERD) test battery ${ }^{62}$. Reliability was estimated, and intraclass correlation values ranged from 0.79 in the shuttle-run test, to 0.85 in the handgrip 
test. Age-, and sex-standardized z-scores were computed for each test (the shuttle-run time was inverted), and then summed to obtain a total physical fitness $\mathrm{z}$-score for each individual, as recommended ${ }^{63,64}$.

School characteristics. Information concerning school characteristics was obtained via a questionnaire completed by a school administrator, assisted by a research team member. A modified, and locally adapted, version of the healthy eating and physical activity modules of the healthy school planner designed by the Joint Consortium for School Health was used ${ }^{65}$. The questionnaire included information from five domains: school size and characterization (number of children, number of teachers and school setting); healthy eating and physical activity policies (the existence, or not of policies and practices used by the school board); extracurricular activities (the existence and type of extracurricular activities available in the school); frequency and duration of physical education classes; and school facilities (playground dimension and characterization, multi-sports roofed existence and dimension, number of structures and equipment available for physical education classes). For the present study, we only used information related to: school setting [mixed (reference category) or urban], number of students (continuous variable), policies and practices for physical activity [three categories: no policies nor practices (reference category); only policies; only practices], playground characteristics [with or without obstacles (reference category)], indoor multi-sport [existence or not (reference category)], physical education classes duration [two categories: $<90 \mathrm{~min}$ (reference category) and $\geq 90 \mathrm{~min}$ ], active time during physical education classes (continuous variables), extracurricular activities [two categories: no (reference category) and yes] and availability of school infrastructures outside of school activities [two categories: no (reference category) and yes].

Statistical analysis. Descriptive statistics are reported as means, standard deviations, and percentages as appropriate. Since the data were hierarchical in nature, i.e., participants nested within schools (two-levels), we used a multilevel logistic regression model ( 0 = normal GMC; 1 = below normal GMC scores) with a step-by-step modeling approach with increasing complexity: first, a null model with no predictors was estimated to calculate how much of the total variation in GMC categories was explained by the schools; second, five sequential models were built with varying complexity levels. Model 1 used age, sex and geographical area; Model 2 built on Model 1 and tested for two-way interactions: age-by-sex, age-by-geographical area and sex-by-geographical area; in Model 3 a three-way interaction was added, namely: age-by-sex-by-geographical area; Model 4 included other child-level characteristics such as stunting, body weight status, maturity offset and physical fitness; Model 5 included school-level characteristics. All model parameters were simultaneously estimated using maximum likelihood procedures, and when appropriate covariates were centered at their means as generally advocated ${ }^{66}$. Deviance ( $-2 \log$ likelihood value) was used as a relative measure of model fit, with smaller values indicating a better fit to the data. When comparing nested models, we relied on differences in deviance, which follows a chisquare distribution with degrees of freedom equal to the difference in the number of estimated parameters from both models. Stata 14 was used in all analyses, and the significance level was set at $5 \%$.

Received: 20 April 2021; Accepted: 14 July 2021

Published online: 29 July 2021

\section{References}

1. Robinson, L. E. Motor development, a field with a bright future. Kinesiol. Rev. 7, 115-122 (2018).

2. Lubans, D. R., Morgan, P. J., Cliff, D. P., Barnett, L. M. \& Okely, A. D. Fundamental movement skills in children and adolescents: Review of associated health benefits. Sports Med. 40, 1019-1035 (2010).

3. Ickovics, J. R. et al. Health and academic achievement: Cumulative effects of health assets on standardized test scores among urban youth in the United States. J. Sch. Health 84, 40-48 (2014).

4. Janssen, I. \& Leblanc, A. G. Systematic review of the health benefits of physical activity and fitness in school-aged children and youth. Int. J. Behav. Nutr. Phys. Act. 7, 40 (2010).

5. Bremer, E. \& Cairney, J. Fundamental movement skills and health-related outcomes: A narrative review of longitudinal and intervention studies targeting typically developing children. Am. J. Lifestyle Med. 12, 148-159 (2018).

6. Gallahue, D. L. \& Ozmun, J. C. Understanding Motor Development: Infants, Children, Adolescents, Adults 6th edn. (McGraw-Hill, 2006).

7. Cameron, C. E., Cottone, E. A., Murrah, W. M. \& Grissmer, D. W. How are motor skills linked to children's school performance and academic achievement?. Child. Dev. Perspect. 10, 93-98 (2016).

8. Fernandes, V. R. et al. Motor coordination correlates with academic achievement and cognitive function in children. Front. Psychol. 7, 318 (2016).

9. Cummins, A., Piek, J. P. \& Dyck, M. J. Motor coordination, empathy, and social behaviour in school-aged children. Dev. Med. Child. Neurol. 47, 437-442 (2005).

10. Lingam, R., Hunt, L., Golding, J., Jongmans, M. \& Emond, A. Prevalence of developmental coordination disorder using the DSMIV at 7 years of age: A UK population-based study. Pediatrics 123, e693-700 (2009).

11. Veldman, S. L., Jones, R. A., Chandler, P., Robinson, L. E. \& Okely, A. D. Prevalence and risk factors of gross motor delay in preschoolers. J. Paediatr. Child. Health 56, 571-576 (2020).

12. de Chaves, R. N. et al. Developmental and physical-fitness associations with gross motor coordination problems in Peruvian children. Res. Dev. Disabil. 53-54, 107-114 (2016).

13. Tsiotra, G. D. et al. A comparison of developmental coordination disorder prevalence rates in canadian and greek children. $J$. Adolesc. Health 39, 125-127 (2006).

14. Robinson, L. E. et al. Motor competence and its effect on positive developmental trajectories of health. Sports Med. 45, 1273-1284 (2015).

15. Barnett, L. M. et al. Correlates of gross motor competence in children and adolescents: A systematic review and meta-analysis. Sports Med. 46, 1663-1688 (2016).

16. Reyes, A. C. et al. Modelling the dynamics of children's gross motor coordination. J. Sports Sci. 37, 2243-2252 (2019).

17. Dos Santos, M. A. M. et al. Modeling children's development in gross motor coordination reveals key modifiable determinants. An allometric approach. Scand J. Med. Sci. Sports 28, 1594-1603 (2018). 
18. Chaves, R. et al. Effects of individual and school-level characteristics on a child's gross motor coordination development. Int. J. Environ. Res. Public Health 12, 8883-8896 (2015).

19. Niemistö, D. et al. Environmental correlates of motor competence in children-the skilled kids study. Int. J. Environ. Res. Public Health 16(11), 1989 (2019).

20. Schott, N., Alof, V., Hultsch, D. \& Meermann, D. Physical fitness in children with developmental coordination disorder. Res. Q. Exerc. Sport 78, 438-450 (2007).

21. Joshi, D. et al. Relationship between BMI, waist circumference, physical activity and probable developmental coordination disorder over time. Hum. Mov. Sci. 40, 237-247 (2015).

22. Hiraga, C. Y., Rocha, P. R. H., Ferracioli, M. D. C., Gama, D. T. \& Pellegrini, A. M. Physical fitness in children with probable developmental coordination disorder and normal body mass index. Rev. Bras. Cineantropom. Desempenho Hum. 16, 182-190 (2014).

23. Malina, R. M., Bouchard, C. \& Bar-Or, O. Growth, Maturation and Physical Activity (Human Kinetics, 2004).

24. Gallup, J. L., Gaviria, A. \& Lora, E. Is Geography Destiny?: Lessons from Latin America (Stanford University Press, 2003).

25. Bustamante Valdivia, A., Maia, J. \& Nevill, A. Identifying the ideal body size and shape characteristics associated with children's physical performance tests in Peru. Scand. J. Med. Sci. Sports 25, e155-165 (2015).

26. Donnelly, J. E. \& Lambourne, K. Classroom-based physical activity, cognition, and academic achievement. Prev. Med. 52(Suppl 1), S36-42 (2011).

27. Santos, C. et al. A multilevel analysis of gross motor coordination of children and adolescents living at different altitudes: The peruvian health and optimist growth study. Ann. Hum. Biol. 47, 355-364 (2020).

28. Sugden, D. A. \& Henderson, S. E. Ecological Intervention for Children with Movement Difficulties (Pearson Education Ltd, 2007).

29. Instituto Nacional de Estadística e Informática (INEI) \& Fondo de las Naciones Unidas para la Infancia (UNICEF). Estado de la niñez en el perú ledn (Fondo de las Naciones Unidas para la Infancia, 2011).

30. D'Hondt, E. et al. Gross motor coordination in relation to weight status and age in 5- to 12-year-old boys and girls: A cross-sectional study. Int. J. Pediatr. Obes. 6, e556-564 (2011).

31. Tanner, J. M. Sequence, Tempo, and individual variation in the growth and development of boys and girls aged twelve to sixteen. Daedalus 100, 907-930 (1971).

32. Cole, T. J. Tanner's tempo of growth in adolescence: Recent SITAR insights with the Harpenden Growth Study and ALSPAC. Ann. Hum. Biol. 47, 181-198 (2020).

33. Visser, J., Geuze, R. H. \& Kalverboer, A. F. The relationship between physical growth, the level of activity and the development of motor skills in adolescence: Differences between children with DCD and controls. Hum. Mov. Sci. 17, 573-608 (1998).

34. Bisi, M. C. \& Stagni, R. Development of gait motor control: What happens after a sudden increase in height during adolescence?. Biomed. Eng. Online 15, 47 (2016).

35. Philippaerts, R. M. et al. The relationship between peak height velocity and physical performance in youth soccer players. J. Sports Sci. 24, 221-230 (2006).

36. Beunen, G. et al. Adolescent Growth and Motor Performance. A Longitudinal Study in Belgian Boys (Human Kinetics, 1988).

37. Loko, J., Aule, R., Sikkut, T., Ereline, J. \& Viru, A. Motor performance status in 10 to 17 -year-old Estonian girls. Scand. J. Med. Sci. Sports 10, 109-113 (2000).

38. Quatman-Yates, C. C., Quatman, C. E., Meszaros, A. J., Paterno, M. V. \& Hewett, T. E. A systematic review of sensorimotor function during adolescence: A developmental stage of increased motor awkwardness?. Br. J. Sports Med. 46, 649 (2012).

39. Davies, P. L. \& Rose, J. D. Motor skills of typically developing adolescents: Awkwardness or improvement?. Phys. Occup. Ther. Pediatr. 20, 19-42 (2000).

40. Sharma, B., Chavez, R. C. \& Nam, E. W. Prevalence and correlates of insufficient physical activity in school adolescents in Peru. Rev. Saúde Pública 52, 51 (2018).

41. Stiperski, Z. \& Hruška, T. Social Changes in the Peruvian Amazon due to Foreign Influence, Ecosystem and Biodiversity of Amazonia, Heimo Juhani Mikkola (IntechOpen, 2020).

42. D'Hondt, E. et al. A longitudinal analysis of gross motor coordination in overweight and obese children versus normal-weight peers. Int. J. Obes. 37, 61-67 (2013).

43. Bustamente, A. Variabilidad del crecimiento somático y desempeño motor en escolares de Enseñanza Básica de la región central del Perú (University of Porto, 2012).

44. INEI. Perfil sociodemográfico del Peru, Informe Nacional., https://www.inei.gob.pe/media/MenuRecursivo/publicaciones_digit ales/Est/Lib1539/index.html (2018).

45. El Estado Peruano. Municipalidad Chanchamayo., http://www.munichanchamayo.gob.pe/turismo.php.

46. El Estado Peruano. Municipalidad Junín. https://www.munijunin.gob.pe/.

47. El Estado Peruano. Municipalidad Barranco. https://www.munibarranco.gob.pe/.

48. SENAMHI. Peru Climate Map.https://www.senamhi.gob.pe/.

49. Kiphard, E. J. \& Schilling, F. Koperkoordinationtestfur Kinder (Beltz Test GmbH, 1974).

50. Laukkanen, A. et al. Comparison of motor competence in children aged 6-9 years across northern, central, and southern European regions. Scand. J. Med. Sci. Sports 30, 349-360 (2020).

51. Tchamo, M. E., Moura-Dos-Santos, M. A., Dos Santos, F. K., Prista, A. \& Leandro, C. G. Deficits in anthropometric indices of nutritional status and motor performance among low birth weight children from Maputo City, Mozambique. Am. J. Hum. Biol. 29(3), e22949 (2017).

52. Moreira, J. P. A. et al. Körperkoordinationstest Für Kinder (KTK) for Brazilian children and adolescents: Factor analysis, invariance and factor score. Front. Psychol. 10, 2524 (2019).

53. Schilling, F. (ed jmaia@fade.up.pt) (2015).

54. Butte, N. F., Garza, C. \& de Onis, M. Evaluation of the feasibility of international growth standards for school-aged children and adolescents. J. Nutr. 137, 153-157 (2007).

55. de Onis, M. \& Lobstein, T. Defining obesity risk status in the general childhood population: Which cut-offs should we use?. Int. J. Pediatr. Obes. 5, 458-460 (2010).

56. Mirwald, R. L., Baxter-Jones, A. D., Bailey, D. A. \& Beunen, G. P. An assessment of maturity from anthropometric measurements. Med. Sci. Sports Exerc. 34, 689-694 (2002).

57. Pereira, S. et al. Profiling physical activity, diet, screen and sleep habits in Portuguese children. Nutrients 7, 4345-4362 (2015).

58. Morrissey, J. L., Janz, K. F., Letuchy, E. M., Francis, S. L. \& Levy, S. M. The effect of family and friend support on physical activity through adolescence: A longitudinal study. Int. J. Behav. Nutr. Phys. Act. 12, 103 (2015).

59. Costa, E. S. L., Fragoso, M. I. \& Teles, J. Physical activity-related injury profile in children and adolescents according to their age, maturation, and level of sports participation. Sports health 9, 118-125 (2017).

60. Santos, C. et al. Stunting and physical fitness. The Peruvian health and optimist growth study. Int. J. Environ. Res. Public Health $17,3440(2020)$.

61. Council of Europe. Eurofit: Handbook for the Eurofit Tests of Physical Fitness (Council of Europe, Committee for the Development of Sport, 1993).

62. AAHPERD. Physical educations, recreation and dance. In Health Related Physical Fitness Manual (1980).

63. Huang, Y. C. \& Malina, R. M. BMI and health-related physical fitness in Taiwanese youth 9-18 years. Med. Sci. Sports Exerc. 39, 701-708 (2007). 
64. Pereira, S. et al. Sibling similarity in metabolic syndrome: The portuguese sibling study on growth, fitness, lifestyle and health. Behav. Genet. 49, 299-309 (2019).

65. Joint Consortium for School Health. Healthy School Planner. http://www.healthyschoolplanner.uwaterloo.ca (2012).

66. West, B., Welsch, K. \& Galecki, A. Linear Mixed Models. A Practical Guide using Statistical Software (Chapman \& Hall/CRC, 2007).

\section{Acknowledgements}

The authors thank all the schoolchildren of Barranco, Junín, San Ramon and La Merced who participated in this study. Also, we thank all the students and teachers of the UNE's Physical Education who contributed to the data collection.

\section{Author contributions}

Conceptualization, S.P., C.S. and J.M.; formal analysis, S.P., D.H. and J.M.; investigation, A.B. and J.M.; data curation, A.B.; writing-original draft preparation, S.P., C.S., P.T.K and J.M.; writing—review and editing, S.P., C.S., P.T.K., J.M., D.H., G.T., R.G., O.V. and A.B.J.

\section{Competing interests}

The authors declare no competing interests.

\section{Additional information}

Correspondence and requests for materials should be addressed to S.P.

Reprints and permissions information is available at www.nature.com/reprints.

Publisher's note Springer Nature remains neutral with regard to jurisdictional claims in published maps and institutional affiliations.

(c) (i) Open Access This article is licensed under a Creative Commons Attribution 4.0 International License, which permits use, sharing, adaptation, distribution and reproduction in any medium or format, as long as you give appropriate credit to the original author(s) and the source, provide a link to the Creative Commons licence, and indicate if changes were made. The images or other third party material in this article are included in the article's Creative Commons licence, unless indicated otherwise in a credit line to the material. If material is not included in the article's Creative Commons licence and your intended use is not permitted by statutory regulation or exceeds the permitted use, you will need to obtain permission directly from the copyright holder. To view a copy of this licence, visit http://creativecommons.org/licenses/by/4.0/.

(C) The Author(s) 2021 